\title{
Improved Education and Trainings in the Field of Fire Protection
}

\author{
Roland Iosif Moraru ${ }^{1}$, Mariusz Sroka ${ }^{2, *}$ \\ ${ }^{1}$ University of Petrosani, Management and Industrial Engineering Department, University Street 20, \\ Romania \\ ${ }^{2}$ Technical University of Czestochowa, Faculty of Management, Armii Krajowej 19B, Poland
}

\begin{abstract}
The article presents the characteristics of the subject "Fire and rescue protection" carried out at the Faculty of Management at the Czestochowa University of Technology in the field of "Work Safety and Hygiene". The modified program consists of lectures and exercises and also presents a practical way of implementing the selected issues in a given building. Next, the methodology of research and the results of questionnaire surveys conducted in the target group of students are presented, referring to the improved content and methods of education and training in the field of fire protection. The article ends with conclusions from the conducted research and the proposed concept of activities for the future.
\end{abstract}

\section{Introduction}

Fire protection includes carrying out projects aimed at protecting life, health, property or the environment against fire, natural disaster or other local threat. This is done by preventing the emergence and spread of fire, natural disaster or other local threat, providing manpower and means to fight a fire, natural disaster or other local threat, and carrying out rescue operations. Successful completion of the above tasks requires the functioning of the entire rescue and fire extinguishing system, the medical rescue system and the emergency notification system $[1,2,3,4]$. It should be highlighted that it is the duty of every natural person, legal person, organization or institution using the environment, building, facility or area to protect them against a fire hazard or other local threat. Detailed tasks, duties and requirements in this area are regulated by relevant regulations, laws, legal acts, standards and instructions $[5,6,7]$.

Widely understood fire protection requires an educational system including teaching, education and upbringing $[8,9,10]$. The authors of this study propose changes to the content and teaching methods in the cycle of education of first degree engineering students in the field of health and safety at the subject of fire protection and rescue. The purpose of these changes is to improve the teaching process in the field of fire protection. The research is to answer whether the actions taken, changes and methods are correct and appropriate in the didactic process.

\footnotetext{
* Corresponding author: mariusz.sroka@wz.pcz.pl
} 


\section{General characteristics of the subject: fire protection and rescue}

The subject of fire protection and rescue is conducted in the field of occupational safety and health on the sixth semester of engineering studies of the first degree. It is a subject area with a general academic profile of 15 hours of lectures and 15 hours of exercises. The number of ECTS points that students receive after completing the course is 3 .

The aim of the course is to familiarize students with the principles of fire protection, the fire protection system in Poland and the rules of conduct in the event of a fire and the principles of undertaking rescue and firefighting activities. It is assumed that the achievement of learning outcomes during the didactic process will allow students to skillfully assess fire risks, to act properly in the event of fire and rescue and firefighting activities.

The curriculum contents of lectures were selected in accordance with the guide prepared by the authors on the subject for a given field of study and the corresponding national qualifications framework. They include:

- Basic concepts and terms related to fire and rescue;

- Legal regulations in the field of fire protection and rescue in Poland;

- Basic concepts, phenomena and processes regarding the burning of materials;

- Equipment and other extinguishing media - purpose and rules of use;

- Technical fire-fighting equipment - (fire-fighting water supply, warning systems, fixed fire extinguishing systems, system installations);

- Causes of fires, identification and assessment of fire hazards;

- Rules of conduct in case of a fire;

- Organization and procedures for the evacuation of buildings;

- Organization of fire protection in public facilities;

- Rescue operations during the release of hazardous materials.

The content of the auditorium exercises was selected in accordance with the guide prepared by the authors on the subject for the given field of study and the corresponding national qualifications framework. They include:

- Basic legal regulations concerning fire and rescue protection in Poland - implementation of the legal acts database;

- Technical conditions of buildings and their location in the context of fire protection practical exercises on a construction site;

- Technical and organizational conditions for evacuation from buildings - practical exercises on a construction site;

- Fire-fighting equipment and hand-held extinguishing equipment in public facilities practical exercises on a construction site;

- Rescue operations during emergency events involving hazardous materials - analysis and indication and discussion of rescue procedures.

Particular attention should be paid to the practical form proposed by the authors for the implementation of selected exercises on building objects. The authors depart from the previously strictly theoretical form in favor of a practical local an-site exercise. The improvement of teaching methods in this way gives very positive results, which is confirmed by the research presented below.

\section{Research methodology}

Questionnaire surveys were carried out on 10 and 12 June 2018. Respondents were students of the Faculty of Management at the Czestochowa University of Technology. The groups in which the survey was conducted were selected on purpose. The conditions for participation 
in the research were: studying in the field of occupational safety and health, positive completion of the subject of fire protection and rescue and consent to participate in the research. 34 questionnaires were carried out, of which all questionnaires were classified after eliminating errors, consistency and logic of the answers provided for further analysis. The questionnaire contained 11 questions. Ten questions were closed-ended with the possibility of indicating one answer. One question was an open-ended question. The aim of the conducted research was:

- Determining whether the selection of program content of lectures and exercises on the subject of fire protection and rescue is appropriate;

- Determining the level of understanding of the theoretical and practical knowledge by respondents;

- Evaluation of the practical form of selected exercises;

- Determining the suitability of the information acquired on the subject in terms of increasing the competences and skills of the group of students;

- Determining whether the goals and objectives assumed for the learning outcomes during the didactic classes have been achieved;

- Diagnosing whether the acquired competences will be used in the future work of the surveyed group;

- Getting the answer to the question whether the subject met the expectations of students.

The test results are presented graphically or compiled in tables and analyzed in the chapter below.

\section{Analysis of test results}

The first and second question was aimed at assessing whether the program content of lectures and exercises on the subject of fire protection and rescue are properly selected according to the respondents. A vast majority of respondents (in total for lectures $91 \%$ and for exercises - 97\%) evaluate the selection of program content as appropriate or very good. None of the respondents indicated that the choice of program content lectures and exercises was wrong or insufficient. The test results for this part of the survey are presented in Figure 1.

$\square$ Lectures $\square$ Practice

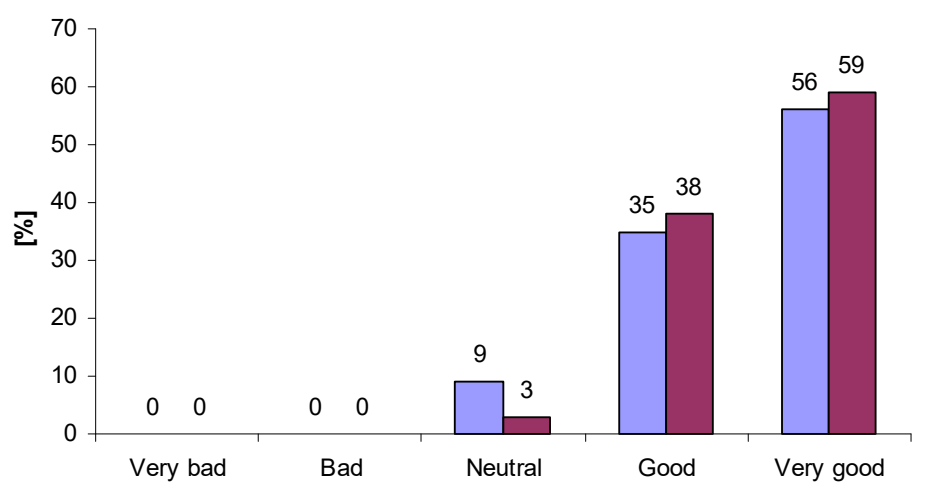

Fig. 1. Evaluation of the selection of program content of lectures and exercises on the subject of fire protection and rescue.

The next two questions concerned the extent to which students improved their theoretical and practical knowledge of the issues discussed in the didactic classes. A vast majority of 
respondents indicated the improvement of their knowledge as good or very good (in total for theoretical knowledge $88 \%$ and for practical knowledge 97\%). The understanding was improved sufficiently by theoretical knowledge by $12 \%$ of respondents, and $3 \%$ by practical knowledge. None of the respondents indicated that the classes did not deepen his knowledge. The results of this part of the survey are summarized in Table 1.

Table 1. Degree of deepening theoretical and practical knowledge in the field of discussed issues.

\begin{tabular}{|l|c|c|}
\hline $\begin{array}{c}\text { Degree of deepening } \\
\text { knowledge }\end{array}$ & $\begin{array}{c}\text { Theoretical knowledge } \\
\text { Indication [\%] }\end{array}$ & $\begin{array}{c}\text { Practical knowledge } \\
\text { Indication [\%] }\end{array}$ \\
\hline Not improved & 0 & 0 \\
\hline Sufficient & 12 & 3 \\
\hline Good & 38 & 41 \\
\hline Very good & 50 & 56 \\
\hline
\end{tabular}

The purpose of the next question was to examine how the respondents evaluate the form proposed by the authors to implement selected issues in a practical way on the designated construction site. This question was one of the most important in the conducted research. The percentage of students surveyed positively evaluating this form of classes was $100 \%$. It should be noted that $76 \%$ indicate a very positive rating. The test results for this part of the survey are presented in Figure 2.

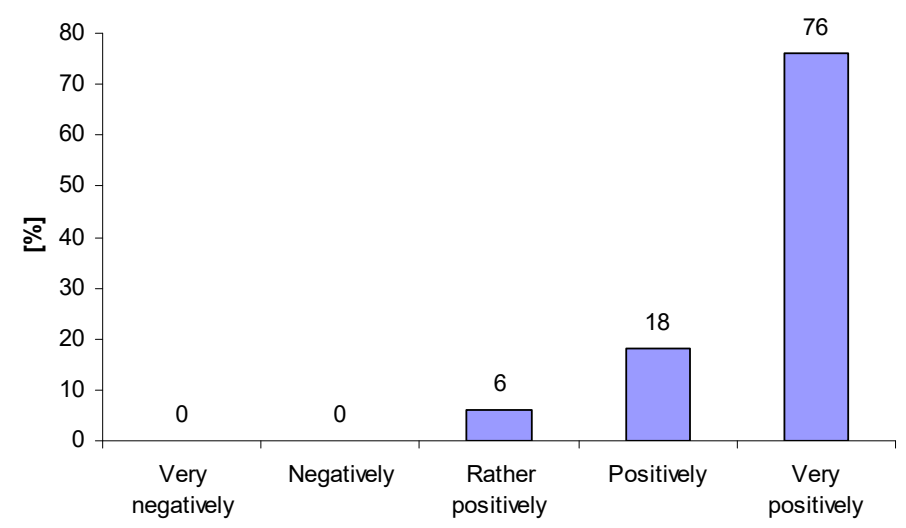

Fig. 2. Assessment of practical classes in the form of a local vision on a construction site.

In the next question, the respondents' task was to assess the suitability of the information acquired on the subject of fire protection and rescue in terms of raising their own competences and skills. $53 \%$ of respondents indicated it as very useful and $41 \%$ as useful. Only $6 \%$ of respondents indicated the answer "moderately useful". It should be noted that none of the respondents indicated the answers: useless and little useful. The test results for this part of the survey are presented in Figure 3.

The next two questions were aimed at getting to know the students' opinions about whether the objectives of the subject were implemented and whether learning outcomes were achieved. This is clearly the answer of $76 \%$ of respondents regarding the achievement of goals and $68 \%$ of the achievement of the effects of didactic classes. This corresponds to $21 \%$ and $29 \%$ respectively. None of the respondents indicated "not" and "definitely not". The results of this part of the survey are summarized in Table 2. 


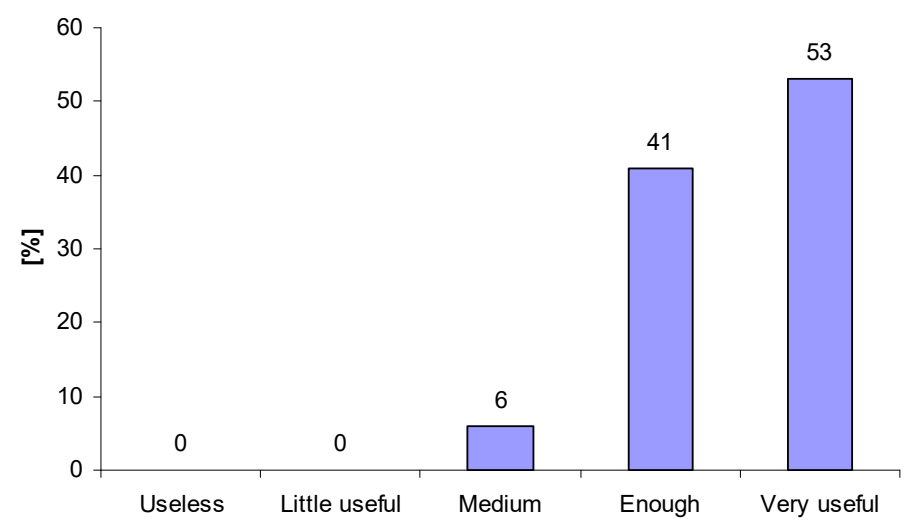

Fig. 3. Usefulness of the acquired knowledge in terms of raising own competences and skills.

Table 2. Realization of goals and achievement of learning outcomes during didactic classes.

\begin{tabular}{|l|c|c|}
\hline \multicolumn{1}{|c|}{ Answers } & $\begin{array}{c}\text { Realization of goals } \\
\text { Indication [\%] }\end{array}$ & $\begin{array}{c}\text { Achieving the effects } \\
\text { Indication [\%] }\end{array}$ \\
\hline Definitely not & 0 & 0 \\
\hline Not & 0 & 0 \\
\hline Hard to say & 3 & 3 \\
\hline Yes & 21 & 29 \\
\hline Definitely yes & 76 & 68 \\
\hline
\end{tabular}

In the next question, the respondents' task was to indicate whether the acquired competences during the didactic classes will be used in professional work. $55 \%$ of the respondents answered that "definitely yes" and 30\% that "yes". 15\% answered that "it's hard to say". None of the respondents indicated "no" and "definitely not". The results of the survey for this question are presented in Figure 4.

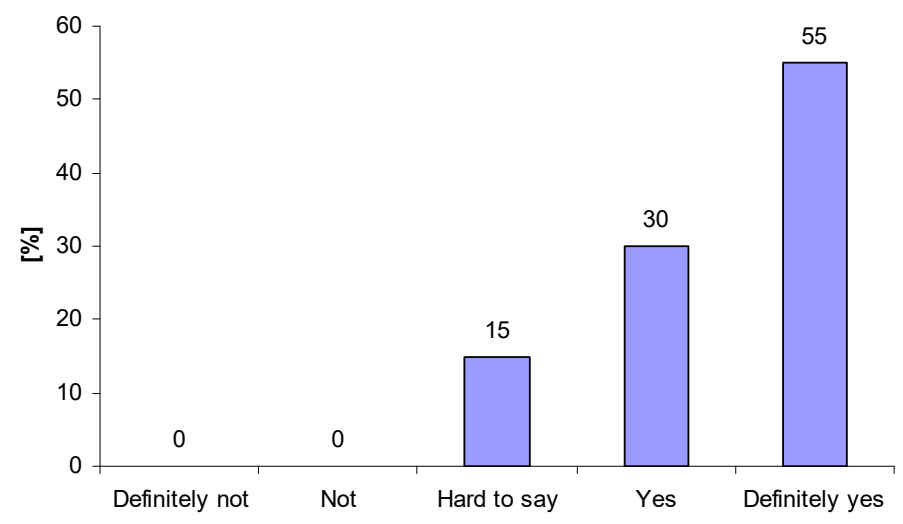

Fig. 4. Use of acquired competences in professional work.

In the last closed question of the questionnaire the respondents' opinion on the fulfillment of expectations regarding the subject of fire protection and rescue was examined. The percentage of respondents indicating that the item met their expectations in to a satisfactory degree is $65 \%$. $26 \%$ of respondents indicate the degree of relevance to expectations, and $9 \%$ of respondents assess this level sufficiently. None of the participants of the study 
indicated that the subject did not meet his expectations or did not meet them sufficiently. The results of the survey for this survey question are presented in Figure 5.

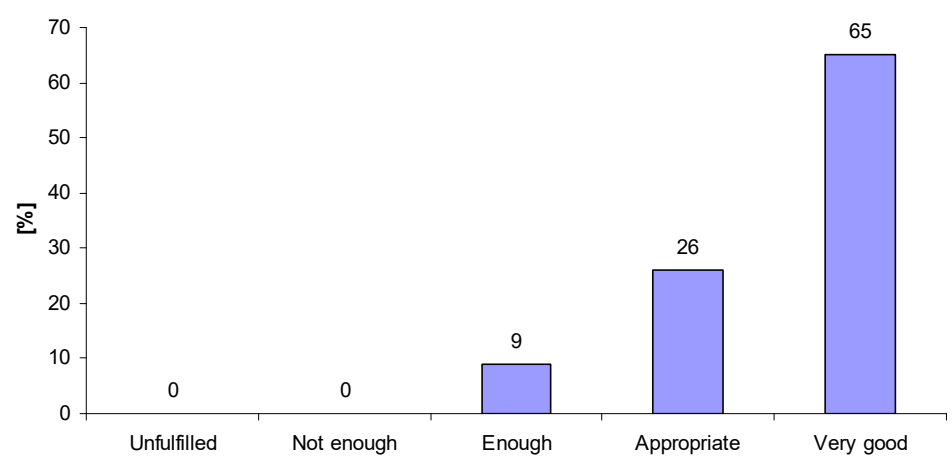

Fig. 5. Degree of meeting respondents' expectations in relation to the subject of fire protection and rescue.

The questionnaire contained one open-ended question, in which the respondents were free to comment and submit their own comments and suggestions regarding the whole training in the field of fire protection. Unfortunately, the answers provided in this part of the questionnaire did not contain a significant research element, therefore, they were not included in this study.

\section{Summary}

The conducted research clearly indicates that it was appropriate to modify the content of teaching and teaching methods of the subject of fire protection and rescue. Respondents rated highly the correct choice of program content, the degree of theoretical and practical knowledge, the usefulness of this knowledge in terms of raising their own competences and skills as well as usefulness in their professional work. The practical method for the implementation of selected issues was rated particularly highly.

Very important was also the highly satisfactory commitment of the participants during the course and the final grades for the subject.

The intention of the authors in the future is to extend the classes in the field of fire protection and rescue to illustrative, laboratory and simulation methods.

\section{References}

1. D. J. Neal, K. T. Stiles, J. V. Salazar, IFSJLM, 11 (2017)

2. W. Lewis, FE, 168, 4 (2015)

3. R. Holmgren, TP\&E, 25, 2 (2016)

4. M.Sommer, O. Nja, JWL, 23, 7 (2011)

5. R. Finger, j.r., FE, 169, 4 (2016)

6. I. Grabara, PJMS, 10, 1 (2014)

7. K. L. Rossler, A. R. Duvall G. Sankaranarayanan. NE (2018)

8. J. Linder, MFC 49, 1 (2012)

9. T. Kiurski, FE 163, 1 (2010)

10. M. Kennedy, AS\&U, 85, 8 (2013) 